LAW RENCE LIVERMORE N A TION A L LABORATORY

An Analysis of the Mt. Meron Seismic Array

M. E. Pasyanos, F. Ryall

January 15, 2008 
This document was prepared as an account of work sponsored by an agency of the United States government. Neither the United States government nor Lawrence Livermore National Security, LLC, nor any of their employees makes any warranty, expressed or implied, or assumes any legal liability or responsibility for the accuracy, completeness, or usefulness of any information, apparatus, product, or process disclosed, or represents that its use would not infringe privately owned rights. Reference herein to any specific commercial product, process, or service by trade name, trademark, manufacturer, or otherwise does not necessarily constitute or imply its endorsement, recommendation, or favoring by the United States government or Lawrence Livermore National Security, LLC. The views and opinions of authors expressed herein do not necessarily state or reflect those of the United States government or Lawrence Livermore National Security, LLC, and shall not be used for advertising or product endorsement purposes.

This work performed under the auspices of the U.S. Department of Energy by Lawrence Livermore National Laboratory under Contract DE-AC52-07NA27344. 


\section{An Analysis of the Mt. Meron Seismic Array}

Michael E. Pasyanos and Flori Ryall

Lawrence Livermore National Laboratory

\section{Introduction}

We have performed a quick analysis of the Mt. Meron seismic array to monitor regional seismic events in the Middle East. The Meron array is the only current array in the Levant and Arabian Peninsula and, as such, might be useful in contributing to event location, identification, and other analysis. Here, we provide a brief description of the array and a review of the travel time and array analysis done to assess its performance.

\section{Array Description}

The Mt. Meron array is a small aperture seismic array located in northern Israel (Figure 1). A three-component broadband station (Streckeisen STS-2 seismometer) MRNI was originally installed in March 1998. This station has a sampling rate of $20 \mathrm{sps}$ and a long-period corner of about $100 \mathrm{sec}$. Later (January 2004), the site was expanded into a 16 element array (Figure 2). The array consists of three rings: a 5 element A-ring (MMA0, MMA1, etc.), a 4 element B-ring, and a 7 element C-ring, as well as a central broadband station MMA0B. Each of the elements consists of a single-component (vertical) Guralp CMG-3ESPV sensor (http://www.guralp.net/products/3ESP/). These stations have sampling rates of $40 \mathrm{sps}$ and corner of what appears to be about $10 \mathrm{sec}$, although it appears that the response that we have for this instrument might not be completely correct (Figure 3). The central broadband station is a Guralp CMG-3TB (http://www.guralp.net/products/3TB/). This station also has a sampling rate of $40 \mathrm{sps}$, but has a corner of about $100 \mathrm{sec}$. A comparison of the instrument responses is shown in Figure 3. The overall size of the array is about $3 \mathrm{~km}$ across with an average station spacing of about $0.5 \mathrm{~km}$. The array is also designated as station AS49 (auxiliary seismic station 49) of the International Monitoring System (IMS) of the Comprehensive NuclearTest-Ban Treaty Organization (CTBTO). 


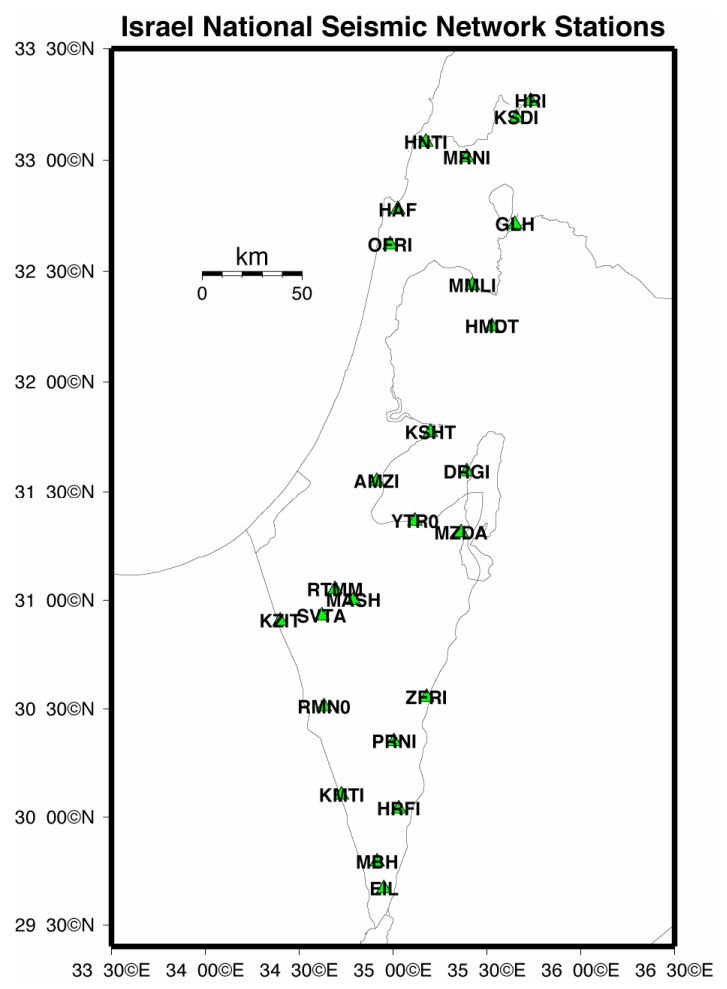

Figure 1. Map of the Israel National Seismic Network. The general location of the Mt. Meron array is indicated by MRNI in the north.

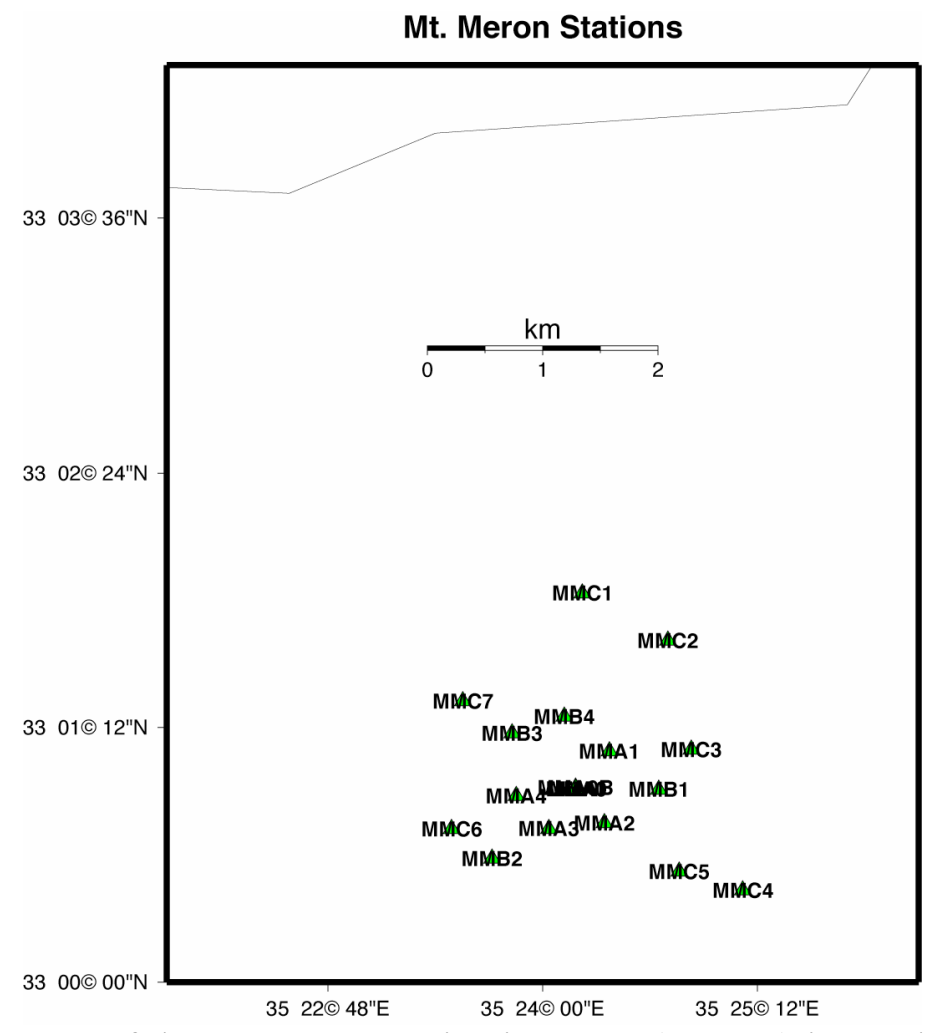

Figure 2. Map of the Mt. Meron Seismic Array (MMAI) in northern Israel. 


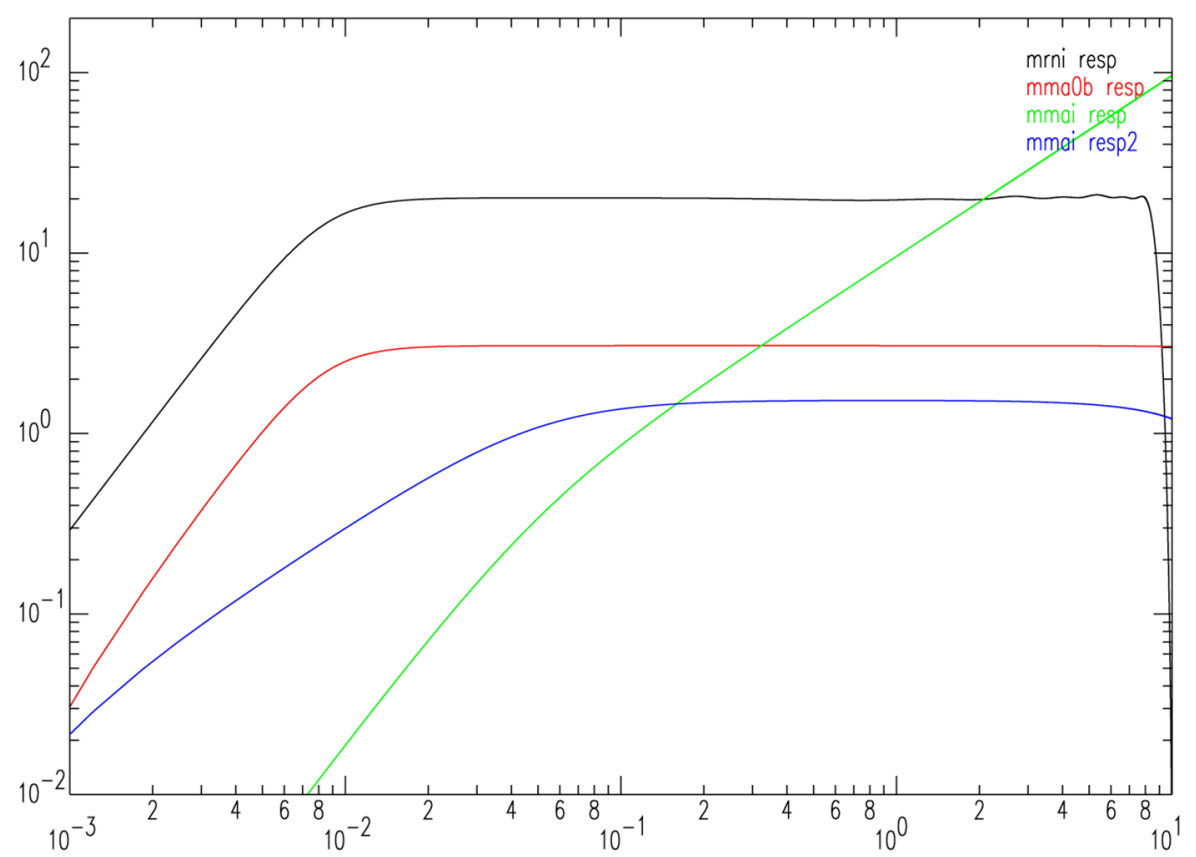

Figure 3. Instrument responses of stations at the Mt. Meron array and nearby stations. Station MRNI is plotted in black, station MMA0B in red, and responses of array elements are in green (original) and blue (zero added to response).

The rule of thumb for array sensitivity is that, in order to reliably record a phase, half the wavelength should be between the minimum array distance and the maximum array distance (total array) aperture.

$$
\operatorname{dist}_{\min } \leq(\lambda / 2) \leq \text { dist }_{\max }
$$

Using values of 0.5 and $3 \mathrm{~km}$ for dist $t_{\min }$ and dist $\mathrm{max}_{\max }$, the array will have sensitivity to periods between 1.3 and $8 \mathrm{~Hz}$ for the regional Pn phase (velocity assumed to be 8.0 $\mathrm{km} / \mathrm{s}$ ), periods between 1.1 and $6.5 \mathrm{~Hz}$ for the regional Pg phase (velocity assumed to be $6.5 \mathrm{~km} / \mathrm{s}$ ), periods between 0.75 and $4.5 \mathrm{~Hz}$ for the regional Sn phase (velocity assumed to be $4.5 \mathrm{~km} / \mathrm{s}$ ), and periods between 0.6 and $3.5 \mathrm{~Hz}$ for the regional $\mathrm{Lg}$ phase (velocity assumed to be $3.5 \mathrm{~km} / \mathrm{s}$ ).

For the faster propagating teleseismic phases $\mathrm{P}$ and $\mathrm{S}$ just after the crossover (assumed velocities of 10.0 and $5.8 \mathrm{~km} / \mathrm{s}$, respectively), the frequencies of sensitivity are between 1.7 and $10 \mathrm{~Hz}$ for teleseismic $\mathrm{P}$ and between 1.0 and $5.8 \mathrm{~Hz}$ for teleseismic $\mathrm{S}$.

All of these ranges are in the flat part of the spectrum between the instrument corner and the Nyquist frequency for the array elements.

\section{Data Quality}

In general, the Mt. Meron array is located in a fairly noisy site. The noise is probably a combination of nearby cultural noise and the fact that the array is located about $20 \mathrm{~km}$ 
from the Mediterranean coast and a similar distance from the Dead Sea Fault Zone (DSFZ). Figure 4 compares the signals from an event in southern Iran $\left(\sim 20^{\circ}\right.$ away) for the array beam (top), a single element of the array (middle), and a nearby single station EIL (bottom). Note that the single Meron element is noisy, the beam is better, but comparable to a single station from a quieter site. Figure $\mathbf{5}$ shows a similar comparison for a different event in the same region. Here the array beam (top) is again compared to a single element (middle) and a single element from the Torodi (TORD) array in Niger (bottom). The station from the TORD array is located $52.5^{\circ}$ from the event, but records it significantly better than the Meron array at $18.8^{\circ}$.

Evid 4710036 S. Iran $\mathrm{h}=0 \mathrm{Km}$ mb 3.7

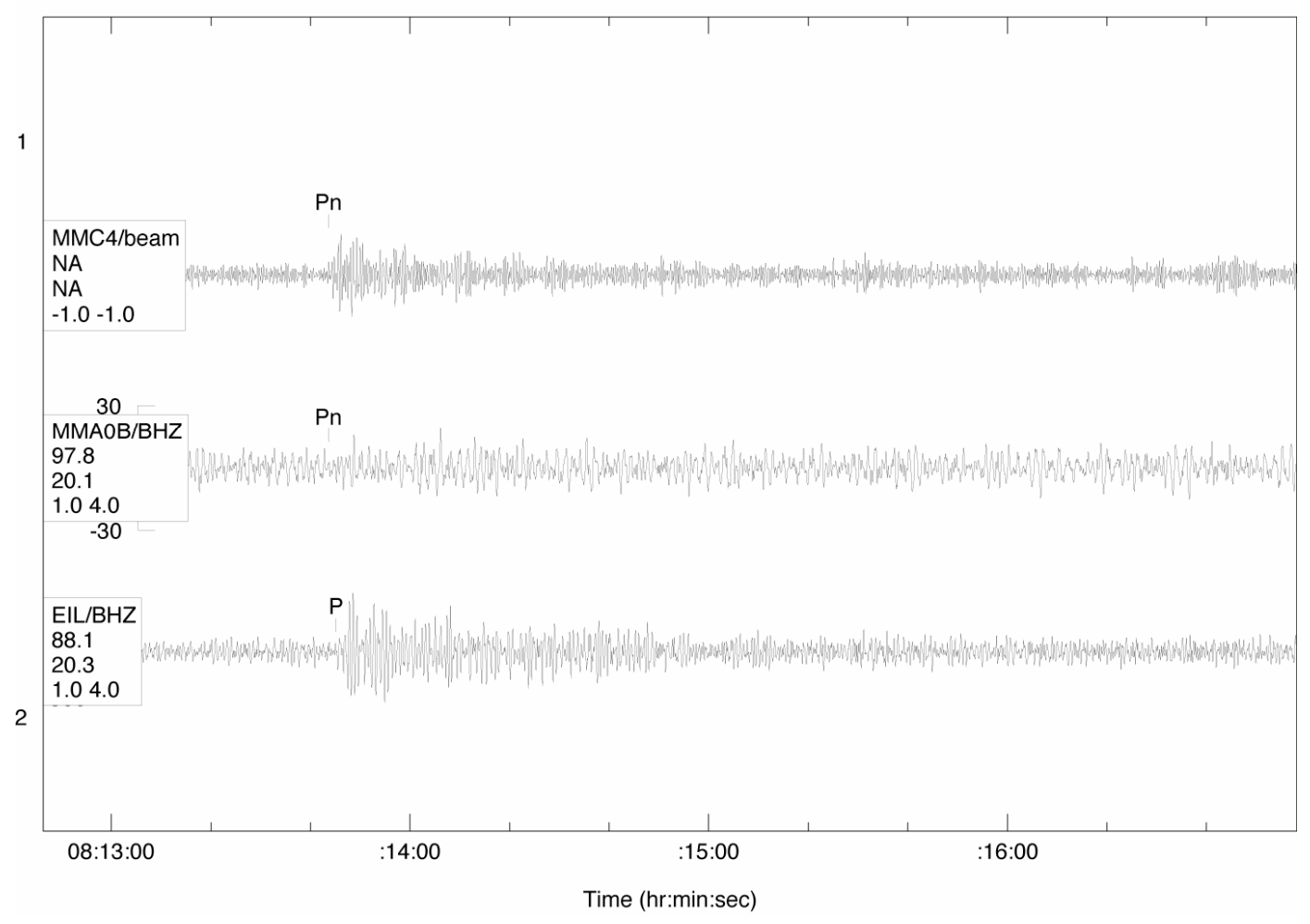

Figure 4. A comparison of Mt. Meron beam, single array element, and EIL single station for a mb 3.7 event in southern Iran. 


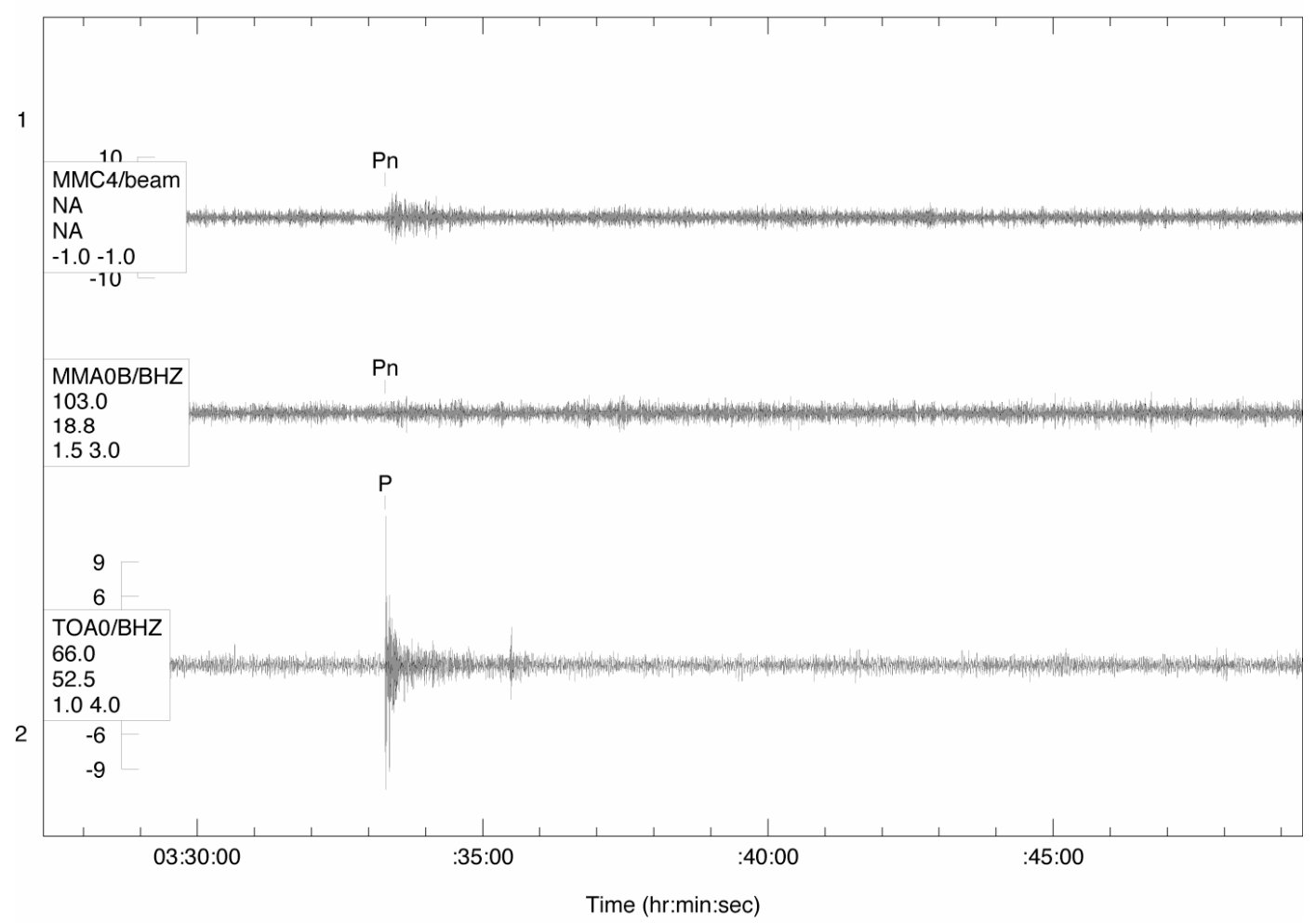

Figure 5. A comparison of Mt. Meron beam, single array element, and single element of the TORD array for a mb 4.0 event in southern Iran.

\section{Data Description}

We currently have one-year of continuous data made available from the Israeli National Data Center (INDC) for the Mt. Meron array, although there are a large number of periods where we do not have all 16 elements of the array. In order to assess the array, we wanted to compare the performance of the array analysis using events in which we have reasonable confidence in the locations. We, therefore, initially limited ourselves to GT events (Bondar et al., 2004) in the region, although some non-GT events were either already analyzed at the MRNI station, and some additional non-GT events were reviewed for further analysis on the crossover. GT or ground truth events are preferred since they are ones in which we have confidence in the lateral mislocation errors, in some statistical sense.

Figure 6 is a map of events in the Middle East that we have analyzed for Mt. Meron. There are a total of 72 events, with most (60) recorded at regional distances (where Pn is the first arrival), only a handful at teleseismic (11) distances ( $\mathrm{P}$ as first arrival), and none at local distances (where Pg is the first arrival). There is also one additional regional event which only records a "lone" Lg without any other identifiable phases. Most seismicity occurs along the Zagros Mts in Iran, although a cluster of events is located in the Gulf of Aden oceanic rift. 


\section{Middle East Paths}

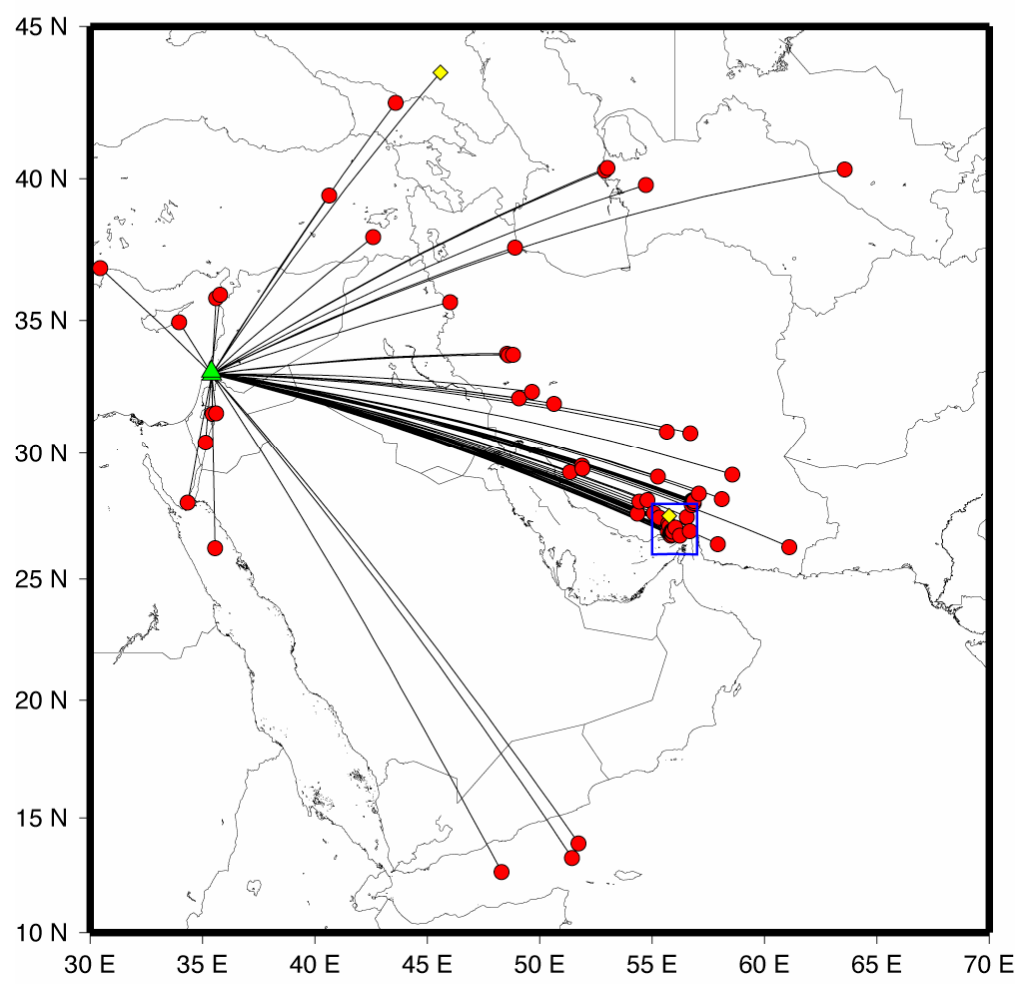

Figure 6. Map showing list of events and paths to Mt. Meron stations. Red circles show nominally shallow $(<60 \mathrm{~km})$ events, yellow diamonds nominally deep $(>=60 \mathrm{~km})$ events, and green triangles the location of Meron stations. The blue box indicates the region near the Strait of Hormuz that was analyzed to determine crossover distance.

\section{Method}

We have made an effort to identify and characterize the seismic phases that are recorded at the Mt. Meron array. When possible, we have used the IASPEI naming convention (Storchak et al., 2003). Generally, we find the usual suite of phases found at local and regional distances $(\mathrm{Pn}, \mathrm{Pg}, \mathrm{Sn}, \mathrm{Lg})$ and teleseismic distances $(\mathrm{P}, \mathrm{S})$. Several events at distances between $2^{\circ}-6^{\circ}$ to the north and northwest of the array, with paths that cross the Mediterranean Sea, recorded a short period (2-3 Hz) arrival at $0.4-2.4 \mathrm{sec}$ after Pn. This phase was labeled Px, and is likely some phase conversion related to the subducting African slab along the Cyprean Arc in the eastern Mediterranean. In at least one case, we have identified higher-mode surface waves which we have labeled M2 after Oliver and Ewing (1957). As a dispersive wave, the timing is not significant, only the presence of the phase. 

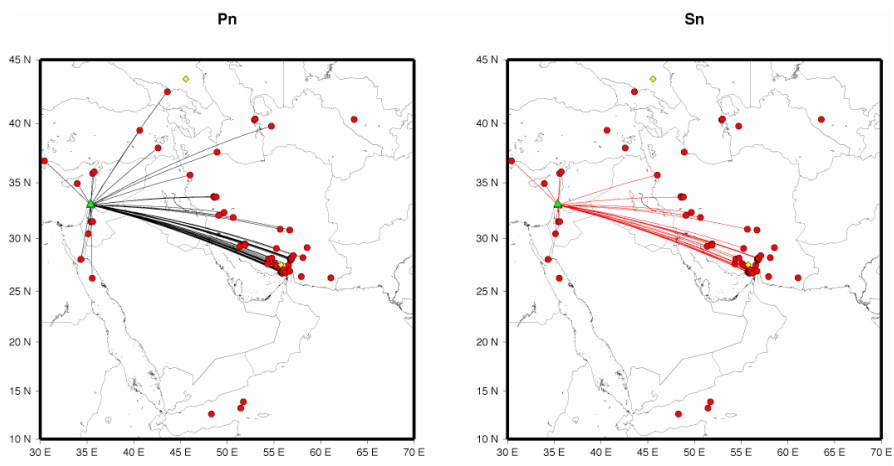

Pg

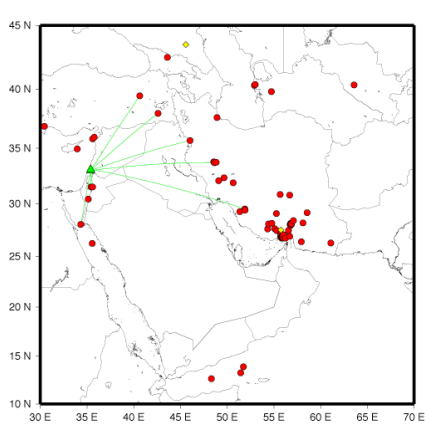

Lg
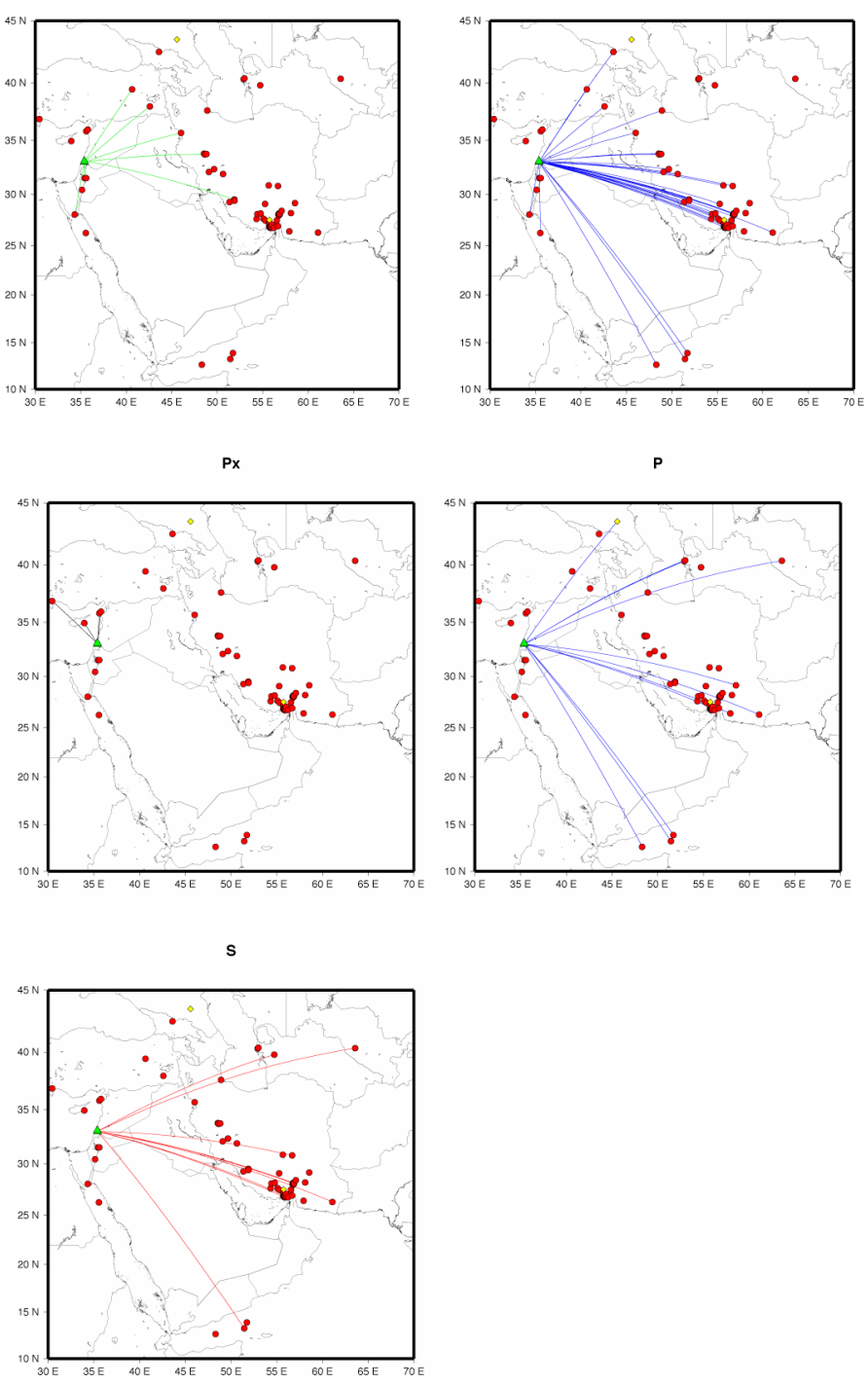

Figure 7. Maps showing phases of individual phases Pn, Sn, Pg, Lg, Px, P, and S.

We performed frequency-wavelength (f-k) analysis for events recorded at the Mt. Meron array. The general procedure is described here. The analysis was performed using Geotool (Henson and Coyne, 1993) with all the available short period elements in 
the array. As an aid in selecting the appropriate window for the calculation, the traces were first sorted according to distance and aligned in time. Window length was selected by trial and error, and ranged from 1-8 sec for Pn, 4-8 sec for Pg, 1.5-2 sec for Px, and 3$8 \mathrm{sec}$ for teleseismic P. Longer windows were generally needed for the S-phases. Window lengths ranging from 3.5-15 sec were used for Sn, 10-20 sec for Lg, and 15-20 sec for teleseismic S.

Filtering the data also played a large part in the $\mathrm{f}-\mathrm{k}$ analysis. When possible, the analysis was performed on unfiltered data, but this was not feasible with many of the smaller events. In instances where filters were needed, the filters used were Butterworth, third order, causal and narrow band. For Pn, filtering was used about $70 \%$ of the time, with the 1.5-3 Hz filter band utilized the most. $\mathrm{Pg}, \mathrm{Px}$, and teleseismic $\mathrm{P}$ phases were mostly unfiltered. For Sn, filtering was needed about $90 \%$ of the time, with the $1.5-3 \mathrm{~Hz}$ filter band used the most. Teleseismic S was mostly unfiltered, but Lg used filtering 90\% of the time, with the $0.05-0.50 \mathrm{~Hz}$ filter band the most commonly selected.

\section{Travel Time Analysis}

The paths of individual phases are shown in Figure 7. It is clear that $\mathrm{Sn}$ is generally found in fewer paths than Pn, especially those crossing eastern Turkey and northwest Iran. This area has been fund to have no mantle lithosphere (Şengör et al., 2003; Gok et al., 2007), which results in Sn blockage. Lg is more prevalent than Pg and propagates out to teleseismic distances to the Gulf of Aden, but does not propagate across the thinner oceanic crust in the Mediterranean and Caspian Sea. P is mostly observed for events at teleseismic distances, but a few others have been labeled as such because they are from deep events at regional distances. $\mathrm{Px}$ is only found from paths crossing the Mediterranean.

Overall, we have $11 \mathrm{P}$ phases, $58 \mathrm{Pn}, 10 \mathrm{Pg}, 4 \mathrm{Px}, 9 \mathrm{~S}, 35 \mathrm{Sn}, 33 \mathrm{Lg}$, and one M2 phase. The colored lines drawn to fit the data have velocities of $8.14 \mathrm{~km} / \mathrm{s}, 5.71 \mathrm{~km} / \mathrm{s}$, $4.65 \mathrm{~km} / \mathrm{s}$, and $3.30 \mathrm{~km} / \mathrm{s}$ for $\mathrm{Pn}, \mathrm{Pg}, \mathrm{Sn}$, and $\mathrm{Lg}$, respectively, with Pn and Sn having a non-zero intersection with the y-axis at $0 \mathrm{~km}$ distance (Figure 8). 


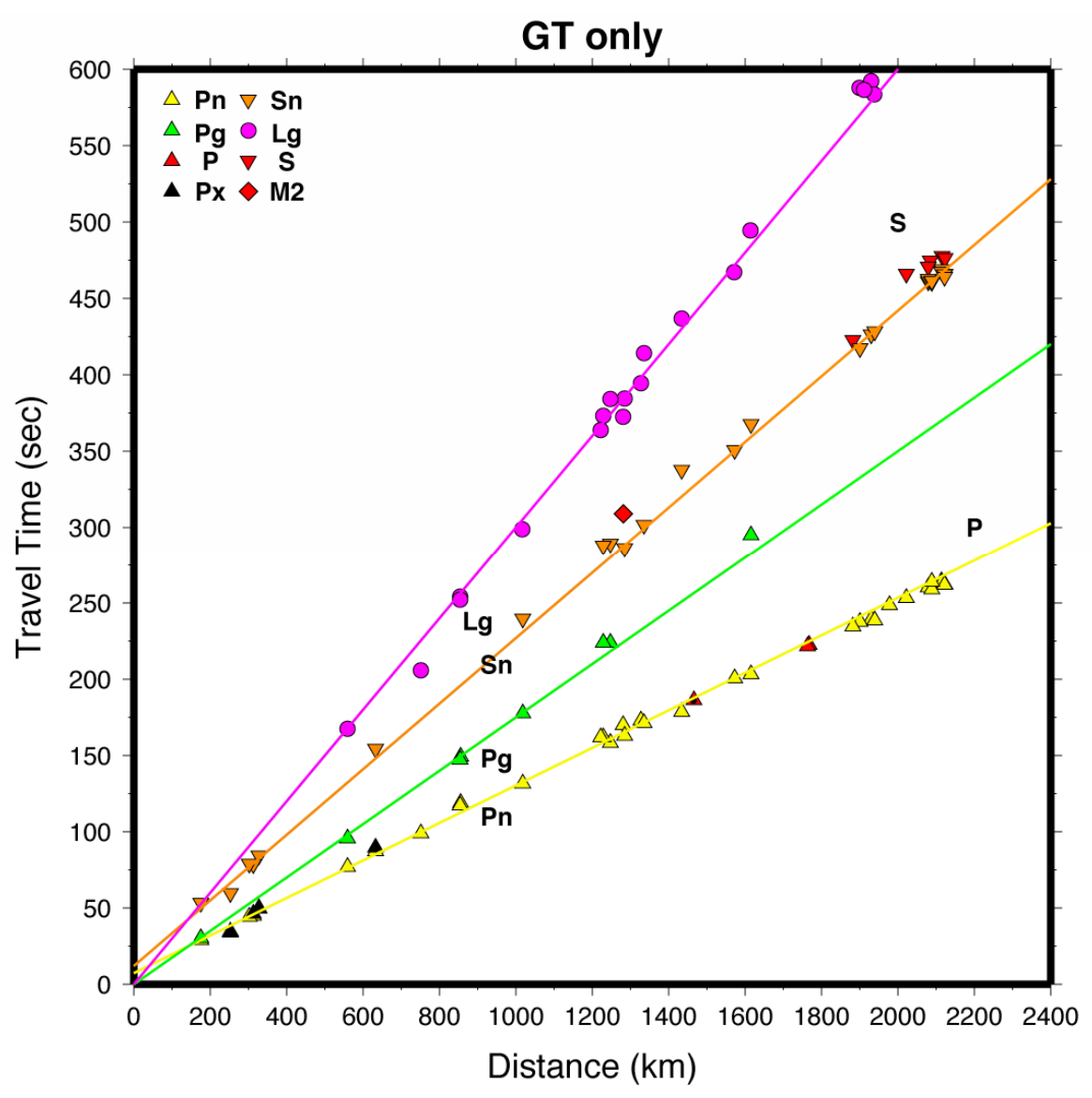

Figure 8. Travel time plot for phases recorded at Meron stations (including MRNI and MMA0B) for GT events. Phases are identified by color-coded symbols.

We test the observed travel times against travel times predicted from the GII (Geophysical Institute of Israel) model (Gitterman et al., 2001), which is used to locate local earthquakes. This model (shown in Table 1 and Figure 9) consists of three layers over a half-space, has a $28.2 \mathrm{~km}$ thick crust with $2.1 \mathrm{~km}$ of sediment, and an upper mantle velocity of $7.90 \mathrm{~km} / \mathrm{s}$. Travel times were generated using the TauP program (Crotwell et al., 1999). The model does an adequate job of fitting Pn, Pg, and $\mathrm{Sn}$ at regional distances, although there are large variations in Lg travel times that are unmodeled by a 1-D velocity model (Figure 10). At far regional distances, the model fits out to epicentral distances of about $16^{\circ}$, but requires significantly faster velocities to fit the travel times beyond this.

Table 1. GII Velocity Model (Gitterman et al., 2001)

\begin{tabular}{|c|c|c|}
\hline $\begin{array}{c}\text { Depth } \\
(\mathrm{km})\end{array}$ & $\begin{array}{c}\text { P-wave velocity } \\
(\mathrm{km} / \mathrm{s})\end{array}$ & $\begin{array}{c}\text { S-wave velocity } \\
(\mathrm{km} / \mathrm{s})\end{array}$ \\
\hline 0 & 3.50 & 1.97 \\
\hline 2.1 & 5.70 & 3.20 \\
\hline 17.7 & 6.40 & 3.60 \\
\hline 28.2 & 7.90 & 4.44 \\
\hline
\end{tabular}




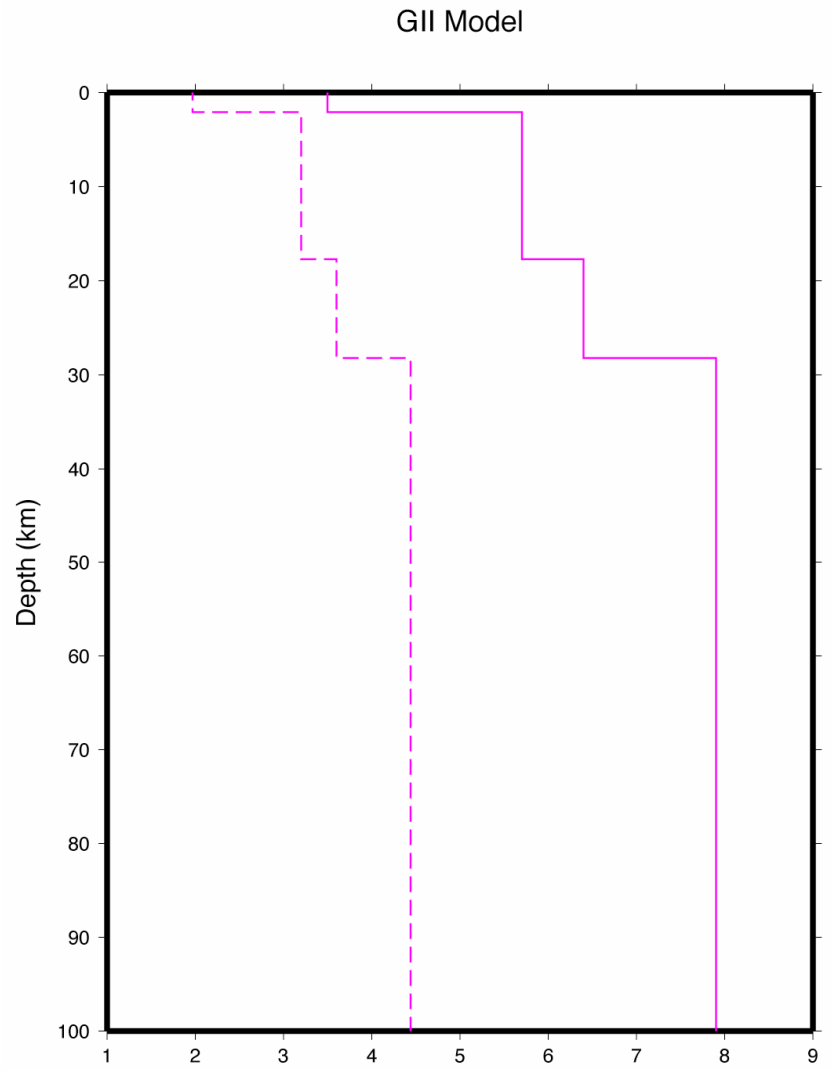

Figure 9. Velocity depth profile of GII model (Gitterman et al., 2001). P-wave velocities are in solid lines, and S-wave velocities are in dashed lines. 


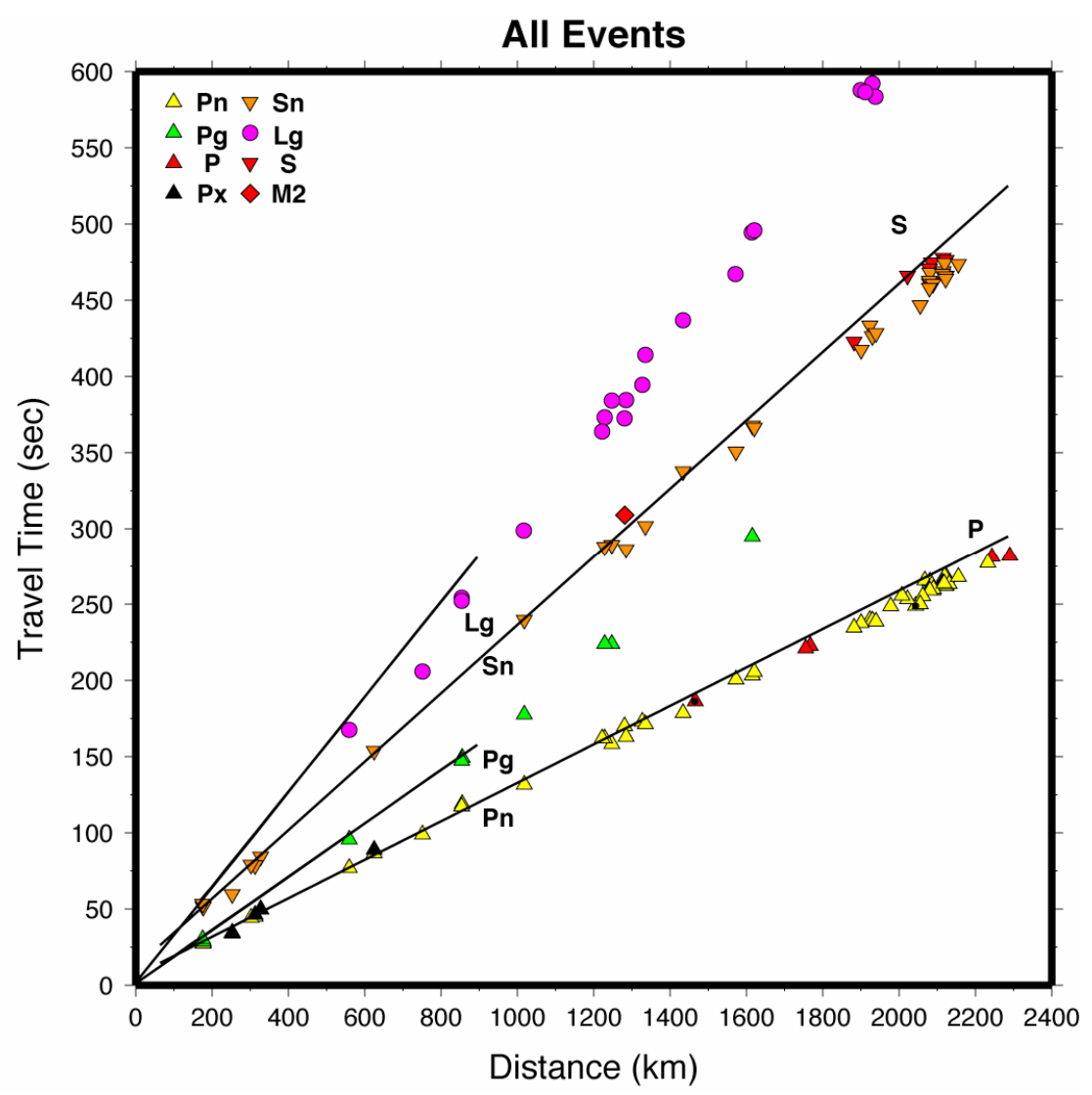

Figure 10. Travel times for phases recorded at Meron stations for all events. Curves are the travel times predicted from the GII model. Symbols are the same as in Figure 8.

\section{Array Analysis}

Array analysis results were obtained for a total of 64 events recorded at the MMAI array. If the apparent velocities of the phases determined by f-k analysis are consistent for each seismic phase and don't overlap with other phases, this can be very useful in the identification of phases. Unfortunately, the results (Figure 11 and summarized in Table 2) are not very encouraging. Pn had apparent velocities ranging from $6.21-9.57 \mathrm{~km} / \mathrm{s}$, a huge range considering that one would expect this to be around $8.0 \mathrm{~km} / \mathrm{s}$. Pg had velocities ranging from $6.80-7.52 \mathrm{~km} / \mathrm{s}$. Sn had velocities ranging from $2.65-4.87$ $\mathrm{km} / \mathrm{s}$. Lg had a wide distribution ranging from $2.66-4.75 \mathrm{~km} / \mathrm{s}$. The Px phase had an apparent velocity between 7.71 and $9.21 \mathrm{~km} / \mathrm{s}$. Notably, there was very large overlap between seismic phases $\mathrm{Pn}, \mathrm{Pg}, \mathrm{Sn}$, and $\mathrm{Lg}$, which complicates the identification of regional phases. In fact, the overlap between $\mathrm{Sn}$ and $\mathrm{Lg}$ was so large it was all but impossible to distinguish between the two phases based on apparent velocity. Turning to teleseismic phases, we have a range of $8.25-12.85 \mathrm{~km} / \mathrm{s}$ for $\mathrm{P}$ and $4.03-5.26 \mathrm{~km} / \mathrm{s}$ for S. Neither of these separates well from their regional counterparts. 

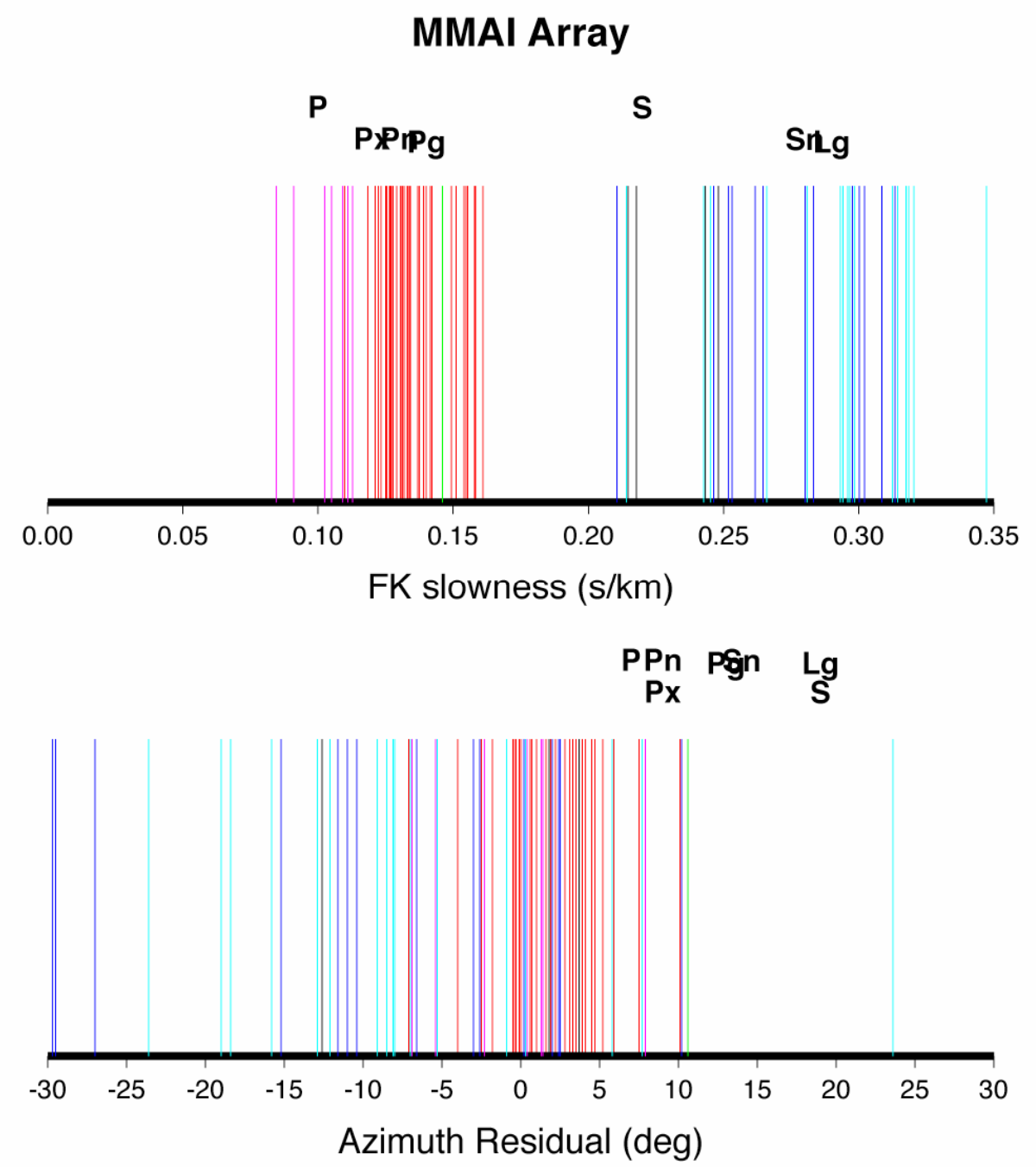

Figure 11. Slowness (top) and azimuth (bottom) residuals from f-k analysis. The colors of the phases on both figures are as follows: P (magenta), Px (dashed blue), Pn (red), Pg (green), S (black), Sn (cyan), and Lg (blue).

Table 2. Summary of $\mathrm{f}-\mathrm{k}$ analysis performed by LLNL. The slowness column provides the mean and standard deviation of all slowness values of that phase. Mean provides the mean in velocity values along with typical values for that phase.

\begin{tabular}{|l|l|l|l|l|l|}
\hline Phase & $\#$ & Slowness $(\mathrm{s} / \mathrm{km})$ & $\begin{array}{l}\text { Mean (typical) } \\
(\mathrm{km} / \mathrm{s})\end{array}$ & Range $(\mathrm{km} / \mathrm{s})$ & $\begin{array}{l}\text { Azimuthal RMS } \\
(\text { degrees })\end{array}$ \\
\hline $\mathrm{P}$ & 11 & $0.101 \pm 0.013$ & $9.90(10.0+)$ & $8.25-12.85$ & 4.5 \\
\hline $\mathrm{Pn}$ & 51 & $0.132 \pm 0.013$ & $7.58(8.0)$ & $6.21-9.57$ & 7.5 \\
\hline $\mathrm{Pg}$ & 4 & $0.140 \pm 0.008$ & $7.14(6.5)$ & $6.80-7.52$ & 13.4 \\
\hline $\mathrm{S}$ & 5 & $0.223 \pm 0.024$ & $4.48(5.8+)$ & $4.03-5.26$ & 20.7 \\
\hline $\mathrm{Sn}$ & 22 & $0.283 \pm 0.044$ & $3.53(4.5)$ & $2.65-4.87$ & 13.3 \\
\hline $\mathrm{Lg}$ & 26 & $0.287 \pm 0.038$ & $3.48(3.5)$ & $2.66-4.75$ & 16.2 \\
\hline $\mathrm{Px}$ & 4 & $0.120 \pm 0.009$ & $8.33(?)$ & $7.71-9.21$ & \\
\hline
\end{tabular}


It also appears that the mantle phases ( $\mathrm{P}, \mathrm{Pn}, \mathrm{S}$, and $\mathrm{Sn}$ ) have slower apparent velocities than is usually typical, but crustal phases $(\mathrm{Pg}, \mathrm{Lg})$ more normal or even faster than typical velocities for these phases. This is normally indicative of the velocity structure in the vicinity of the array and is probably associated with phases propagating through the nearby Dead Sea Rift from the east.

Both Sn and Lg were better recorded on the horizontal channels of the MMA0B station than on the vertical elements of the array. However, since only vertical instruments were available for $\mathrm{f}-\mathrm{k}$ calculations and beaming, azimuth/velocity results for these phases had more scatter than those obtained for first $\mathrm{P}$ arrivals.

Determining backazimuth was similarly challenging at MMAI (Figure 11). RMS residuals for azimuth were 4.5, 7.5, and 13.4 degrees for P, Pn, and Pg, respectively, with some residuals as high as 30 degrees. The first two are small enough that they potentially could be used to reliably estimate backazimuth, if they can be calibrated. Azimuth residuals for S-wave phases were 20.7, 13.3, and 16.2 for $\mathrm{S}, \mathrm{Sn}$, and $\mathrm{Lg}$, respectively, and should probably not be used at all for backazimuth estimation. The poor overall azimuthal determination might explain the look of the apparent velocities on the top figure. The apparent velocity will be at a maximum at the correct azimuth. Off azimuths will yield a slower apparent velocity.

When we subsetted the data for Zagros only events, we did not get substantially different statistical results.

\section{Array Analysis of INDC and Comparison of Results}

A list of all events that we analyzed was sent to the Israeli NDC for them to analyze and to compare the results. Figure 12 and Table 3 provide summaries of the INDC's analysis. There are a couple of things to notice right away. The first is that the INDC focused on P phases. Only six events which had a P-phase had a corresponding S-phase (Sn or S), and no identification was made of $\mathrm{Lg}$ at all. There were also two instances of events picked by LLNL where the event was labeled as "no clear signal" and no phases were picked. These events were in the Strait of Hormuz and Makran. Another observation is that while LLNL had a breakdown of $4 \mathrm{Pg}, 51 \mathrm{Pn}$, and 11 teleseismic P among the events, the INDC had a breakdown of $3 \mathrm{Pg}, 29 \mathrm{Pn}$, and 33 teleseismic P. If borne out, this would indicate that many regional Pn phases are being misidentified as teleseismic P. This is discussed in more detail later on in the report under Crossover Analysis. 

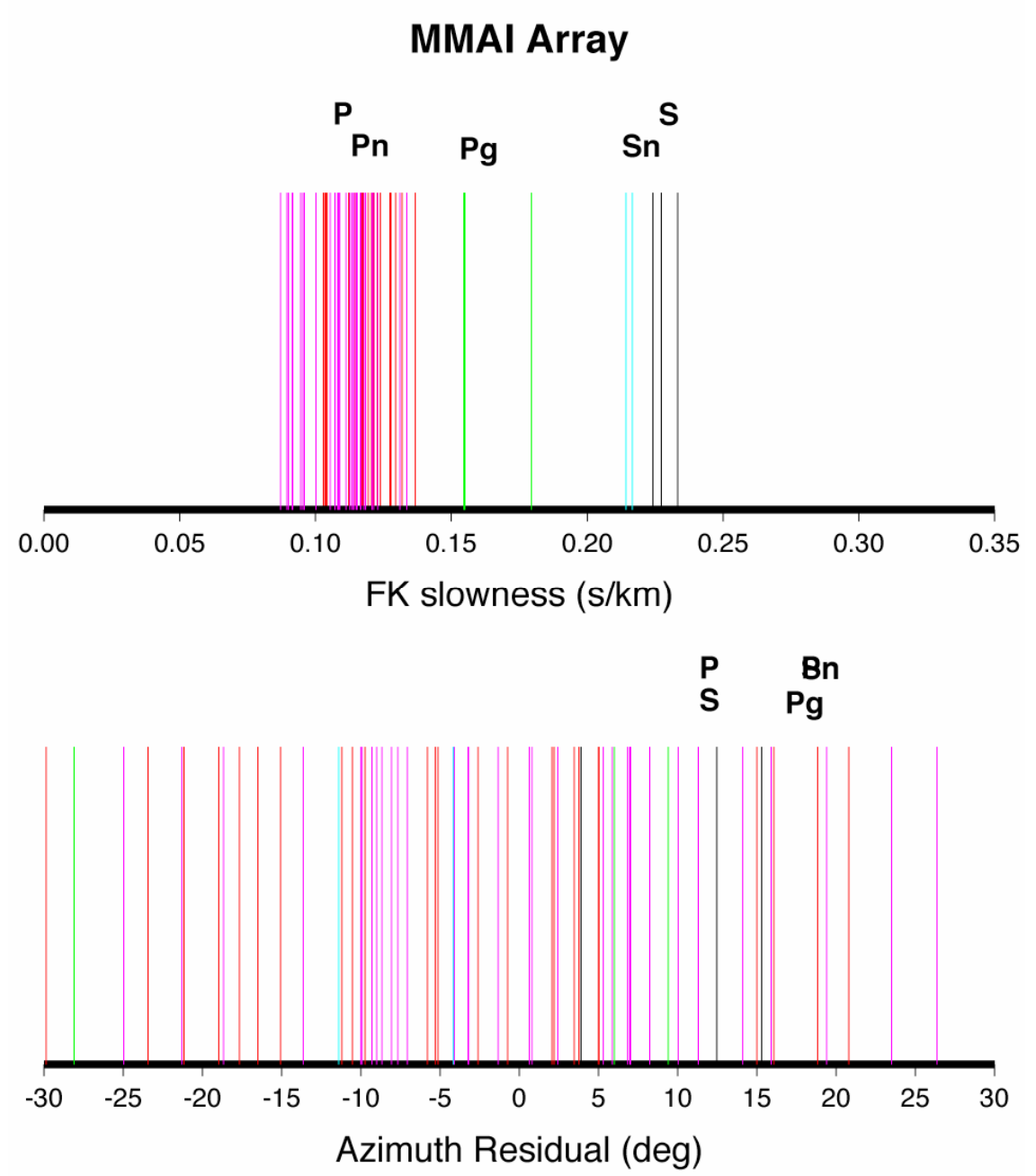

Figure 12. Slowness (top) and azimuth (bottom) residuals from $\mathrm{f}-\mathrm{k}$ analysis performed by INDC. The colors are the same as in Figure 11.

Table 3. Summary of f-k analysis performed by INDC. Columns are the same as Table 2.

\begin{tabular}{|l|l|l|l|l|l|}
\hline Phase & $\#$ & Slowness $(\mathrm{s} / \mathrm{km})$ & $\begin{array}{l}\text { Mean (typical) } \\
(\mathrm{km} / \mathrm{s})\end{array}$ & Range $(\mathrm{km} / \mathrm{s})$ & $\begin{array}{l}\text { Azimuthal RMS } \\
(\text { degrees })\end{array}$ \\
\hline $\mathrm{P}$ & 33 & $0.110 \pm 0.012$ & $9.25(10.0+)$ & $7.48-11.48$ & 12.2 \\
\hline $\mathrm{Pn}$ & 29 & $0.116 \pm 0.009$ & $8.64(8.0)$ & $7.32-9.98$ & 18.8 \\
\hline $\mathrm{Pg}$ & 3 & $0.163 \pm 0.014$ & $6.17(6.5)$ & $5.57-6.47$ & 17.5 \\
\hline $\mathrm{S}$ & 3 & $0.228 \pm 0.005$ & $4.38(5.8+)$ & $4.29-4.46$ & 11.6 \\
\hline $\mathrm{Sn}$ & 3 & $0.218 \pm 0.005$ & $4.58(4.5)$ & $4.46-4.67$ & 19.1 \\
\hline
\end{tabular}

In general, the statistics on the INDC's f-k analysis is similar to that of LLNL's analysis. Standard deviations of estimated slowness of the P, Pn, and Pg phases are very high, and there is large overlap between phases. One significant difference is that the mean value on Pn in the INDC analysis is very high $(8.64 \mathrm{~km} / \mathrm{s})$ compared to the LLNL analysis $(7.58 \mathrm{~km} / \mathrm{s})$ and this is probably due to many teleseismic $\mathrm{P}$ phases improperly labeled as Pn and included in the analysis of this phase. The azimuth residuals are consistently higher than the residuals of the LLNL analysis and could be due to the use of 
filters in the f-k analysis. The statistics on the S-phases are based on a very small number of recorded phases and should not be considered significant.

\section{Crossover Analysis}

We tried as best as possible to ascertain the regional-teleseismic crossover where the phase progresses from a regionally-propagating head wave Pn to a diving ray teleseismic $\mathrm{P}$, as well as the local-regional crossover where the first-arriving phase transitions from crustally-propagating Pg to Pn. Due to the lack of local events in our study, we do not have any information of note on the local-regional crossover, other than to say, as far as we can determine, that it seems consistent with local velocity models such as the GII model (Gitterman et al., 2001).

The only region where we had enough data to do analysis on the regional-teleseismic crossover was in the southern Zagros. The only GT events near the crossover were regional events at $\sim 19^{\circ}$ near the Strait of Hormuz and teleseismic events at $\sim 23^{\circ}$ in the Makran. The crossover was therefore necessarily determined using non-GT events, which may not be well-located. The farthest Pn phase was identified for an event at $19.4^{\circ}$ and, excluding intermediate depth and deep events, the closest $\mathrm{P}$ phase was at $20.2^{\circ}$. The crossover, therefore, is between $19.4^{\circ}$ and $20.2^{\circ}$ (or between 2150 and 2250 $\mathrm{km})$. Note that this value is the crossover distance from events in this region to the Mt. Meron array and that the distance may change when examining events from other azimuths.

This is also consistent with the move-out velocities. In Figure 13, we see that phases out to about $2200 \mathrm{~km}$ have a travel time of about $8.0 \mathrm{~km} / \mathrm{s}$. Around this distance, we see a break where more distant arrivals come in several $\mathrm{km} / \mathrm{s}$ faster than typical Pn velocities. With more data it might be possible to better determine the crossover distance in this region and compare it to crossover distances found in other directions, to see if there is an azimuthal variation. 


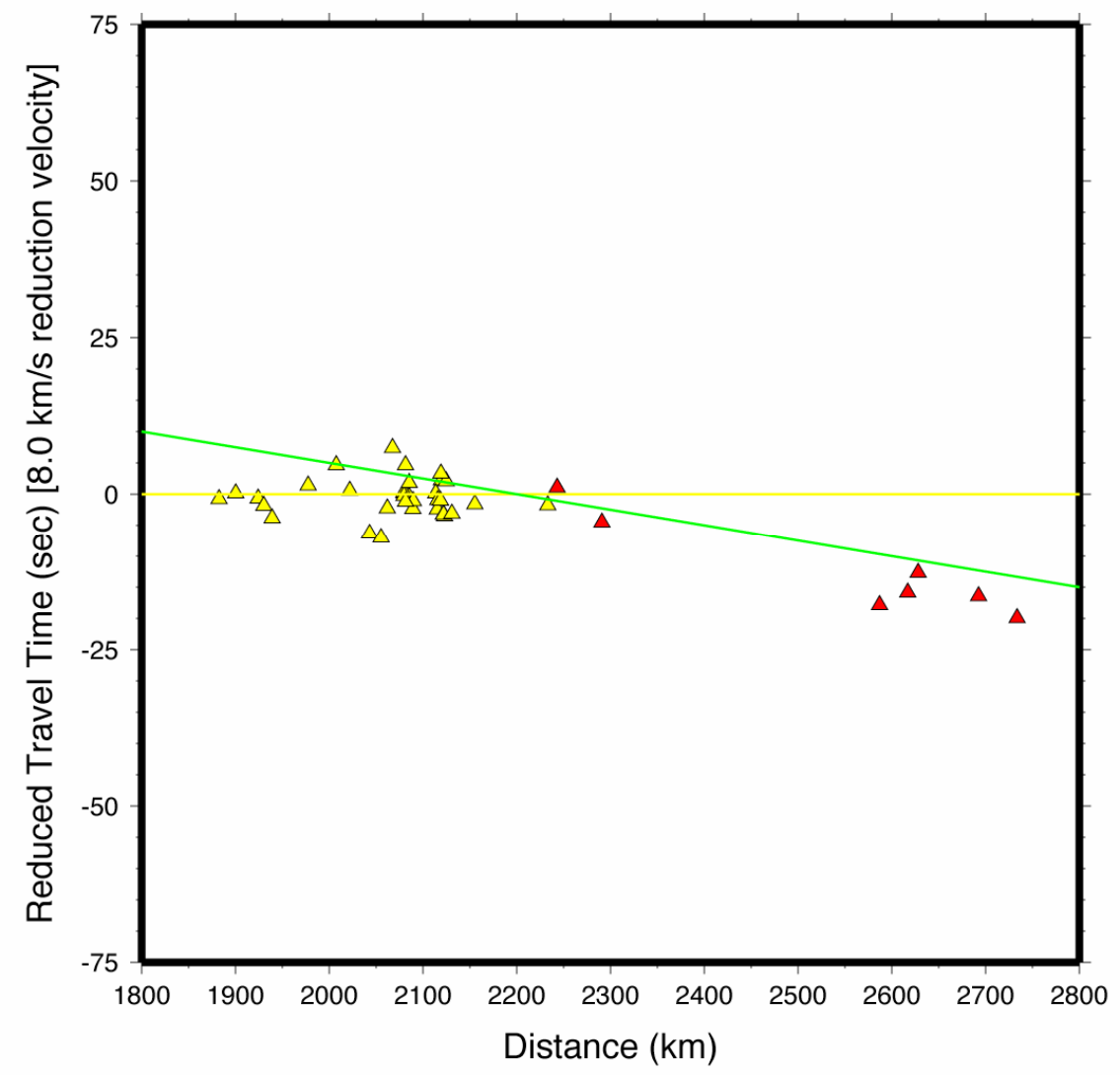

Figure 13. Reduced travel time curves for distances near the regional-teleseismic crossover. A reduction velocity of $8.0 \mathrm{~km} / \mathrm{s}$ is used, which makes Pn moveouts look flat. Symbols are the same as in Figures 8 and 10.

\section{Threshold Analysis}

As part of our analysis, we have examined events from a small region over a range of magnitudes, in order to estimate the approximate magnitude threshold of the array. We classified phase picks from MMAI to the southern Zagros into one of three categories. The first (category one) are picks which have the best signal-to-noise ratio and no beam is necessary to pick an onset; the second (category two) is where the signal is seen on the three-component station, but a beam is used to reliably pick the onset; the final category (category three) has the lowest signal-to-noise ratio and the signal is not seen on the three-component station at all, but only seen on the beam. Below this, the signal is not seen at all, with or without the beam. For Pn, events in category one ranged from mb 4.2 up to 5.8, with an average of around 5.0. Events in category two ranged from 3.8 to 4.8 with an average of around 4.4. Events in category three ranged from 3.6 to 4.6 with an average of around 4.1. The approximate cutoff between categories one and two is about 4.5 and between categories two and three is around 4.0. We generally do not record events below magnitude 3.6. The cutoffs between categories for teleseismic $\mathrm{P}$ are generally the same, although the lowest magnitude threshold is more like mb 3.8.

\section{Miscellaneous}


In our analysis, we noticed that there is a polarity reversal on the vertical component (BHZ channel) of the central broadband station MMA0B, at least during the 2006 time period for which we have data. The MMC3 element was down for close to half of the events that we studied. There were no apparent timing errors at any of the elements of the array.

\section{Recommendations}

Overall, our analysis of the Mt. Meron array is a mixed one. The array definitely allows stacking that can identify signals that would otherwise be missed by a single station. It appears that we can see signals at the array that are about 0.2-0.4 magnitude units lower than what is seen at single array elements. The location of the array, however, is a noisy one and does not demonstrate the full capabilities of an array.

Array analysis is further complicated by complex local structure and phases from events to the east propagating across the Dead Sea Fault Zone. In many ways, the array processing brings the capability of the array up to the performance of a quiet single station, with added phase identification capabilities. Large overlaps in the apparent velocity between phases, however, makes this somewhat of a challenge as well. If a complementary array was located in a quiet region, such as the much quieter region near station EIL (Eilat) to the south, this might be a more powerful regional analysis tool. However, large errors on the backazimuth and the small aperture of the two arrays will probably prevent the use of backazimuths to accurately locate earthquakes through most of the Middle East. With more data and further analysis, it might be possible to do more work on both the local-regional and regional-teleseismic crossovers and to compare velocities and crossovers from different azimuths.

It is recommended that INDC analysts focus on S-phases. Sometimes (not discussed here) P-S times are more stable estimates of distance than the travel time of the first arrival. There also needs to be an increased focus on the proper identification of regional $\mathrm{Pn}$. Finally, it is recommended that they investigate the use of filters for $\mathrm{f}-\mathrm{k}$ analysis. The GII velocity model seems to do an adequate job of fitting travel times out to far regional distances, but a faster velocity model appears required beyond this.

Acknowledgements. This work performed under the auspices of the U.S. Department of Energy by Lawrence Livermore National Laboratory under Contract DE-AC5207NA27344, UCRL-TR-******.

\section{References}

Bondar, I., S.C. Myers, E.R. Engdahl, and E.A. Bergman (2004), Epicentre accuracy based on seismic network criteria, Geophys, J. Int., 156, 483-496.

Crotwell, H.P., T.J. Owens, and J. Ritsema (1999), The TauP Toolkit: Flexible Seismic Travel-time and Raypath Utilities, Seism. Res. Lett., 70, 154-160. 
Gitterman Y., V. Pinsky, and A. Shapira (2001), Improvement in monitoring the CTBT in the Middle East by the Israel Seismic Network, Final Report Contract number DSWA01-97-C-0151, GII Report No. 591/61/97(34).

Gok, R., M.E. Pasyanos, and E. Zor (2007), Lithospheric structure of the continentcontinent collision zone: Eastern Turkey, Geophys. J. Int., doi:10.1111/j.1365246X.2006.03288.x.

Henson, I. and J. Coyne (1993), The Geotool Seismic Analysis System, Proceedings of the 15th Annual Seismic Research Symposium, Boulder, CO, ed. J. Lewkowicz and J. McPhetres.

Oliver, J. and M. Ewing (1957), Higher modes of continental Rayleigh waves, Bull. Seism. Soc. Amer., 47, 187-204.

Şengör, A.M.C., S. Ozeren, E. Zor, and T. Genc (2003), East Anatolian high plateau as a mantle-supported, north-south shortened domal structure, Geophys. Res. Lett., 30(24), 8045, doi:10.1029/2003GL017858.

Storchak, D.A., J. Schweitzer, and P. Borman (2003), The IASPEI standard seismic phase list, Seism. Res. Lett., 74, 761-771. 